\title{
INTRA-EPITHELIAL EPITHELIOMA OF THE CONJUNCTIVA AND THE CORNEA (BOWEN'S DISEASE) HEALED BY CONTACT RADIOTHERAPY*
}

\author{
BY \\ J. François, J. Kluyskens, and M. Rabaey \\ Ophthalmological Clinic, University of Ghent, Belgium.
}

ApART from the classical epitheliomata of the bulbar conjunctiva, whether epidermoid or not, attention should be drawn to the intraepithelial epitheliomata, observed by Bowen since 1912 on the level of the skin and also since observed on the level of the mucous membranes.

McGavic (1942) reported five observations of this type of malignant tumour on the level of the conjunctiva and the cornea. Other cases have been described by Wise (1943), Khanolkar (1946), and Esterman, Laval, and Okrainetz (1947).

This tumour is characterized by a proliferation of epithelial cells within the epithelium itself, there being no perforation of the basal membrane, at least until a long time has elapsed, no invasion of the neighbouring tissues, and no formation of metastases.

The treatment of epibulbar epitheliomata, no matter what the anatomo-pathological type may be, is reputed to be very disappointing. $\mathrm{X}$ rays (Heckel, 1922) and radium (Mattice, 1914; Collins, 1915; Rados and Schinz, 1922) have met with notorious failure. Local excision as well as electrocoagulation is very often followed by a relapse. This is why most authors, including DukeElder (1946) and Mérigot de Treigny (1939), do not hesitate to resort to drastic measures and advise enucleation of the eye-ball or even exenteration of the orbit, if the lesions are very exten sive.

We had the opportunity to observe an intra-epithelial epithelioma of the conjunctiva and the cornea which we were able to heal completely and without sequelae by contact radiotherapy. This success beyond expectation encouraged us to publish our observation, as, the effectiveness of this treatment being confirmed, the prognosis of epibulbar epitheliomata will be wholly modified.

\section{Case History}

On May 18, 1949, a 57-year-old man came to ask advice about a "spot" on the right eye-ball. This "spot" which had first appeared a year before, had started as a little reddish point, which gradually increased as time went on.

* Received for publication February 6, 1950. 


\section{Contact Radiotherapý in Bowen's Disease}

On the level of the paralimbic and infero-external part of the bulbar conjunctiva, a tumour formation was observed, extending from 7 o'clock to 10 o'clock (Fig. 1). It encroached by at least $1 \mathrm{~mm}$. upon the cornea and was $5 \mathrm{~mm}$. broad and $8 \mathrm{~mm}$. high. Its edges

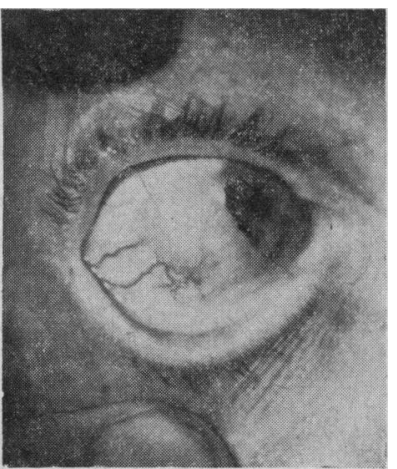

FIG 1.-May 18, 1949. were distinctly marked but a little irregular. Whitish in colour, it showed a granulated, uneven, rather gleaming surface. It did not adhere to the sclerotic and was slightly mobile. Though plainly pro. truding, it was not very thick $(2 \mathrm{~mm}$.) and was of rather firm consistency. On the conjunctival side of the tumour were to be seen some more or less turgescent blood vessels, which give to this area an appearance of very localized hyperaemia : this was not characterized by a diffused redness, but was caused by the presence of some broad, winding veins, which disappeared on the level of the tumour, as they penetrated into it. On the level of the limbus, at 9 o'clock a small and greyer spot was to be seen.

In the biomicroscope (Fig. 2) it could be seen that this spot was essentially composed of an accumulation of many little follicles, more or less regular, juxtaposed in mosaic, white in colour, and centred by a small vascular handle.

Apart from this, the eye presented no anomaly and vision was $10 / 10$.

The left eye was anatomically and functionally normal. Our patient had never been ill, apart from operations for two hernias. He had two daughters, one of 13 years, the other of 16, both in good health. The mother had never had a miscarriage.

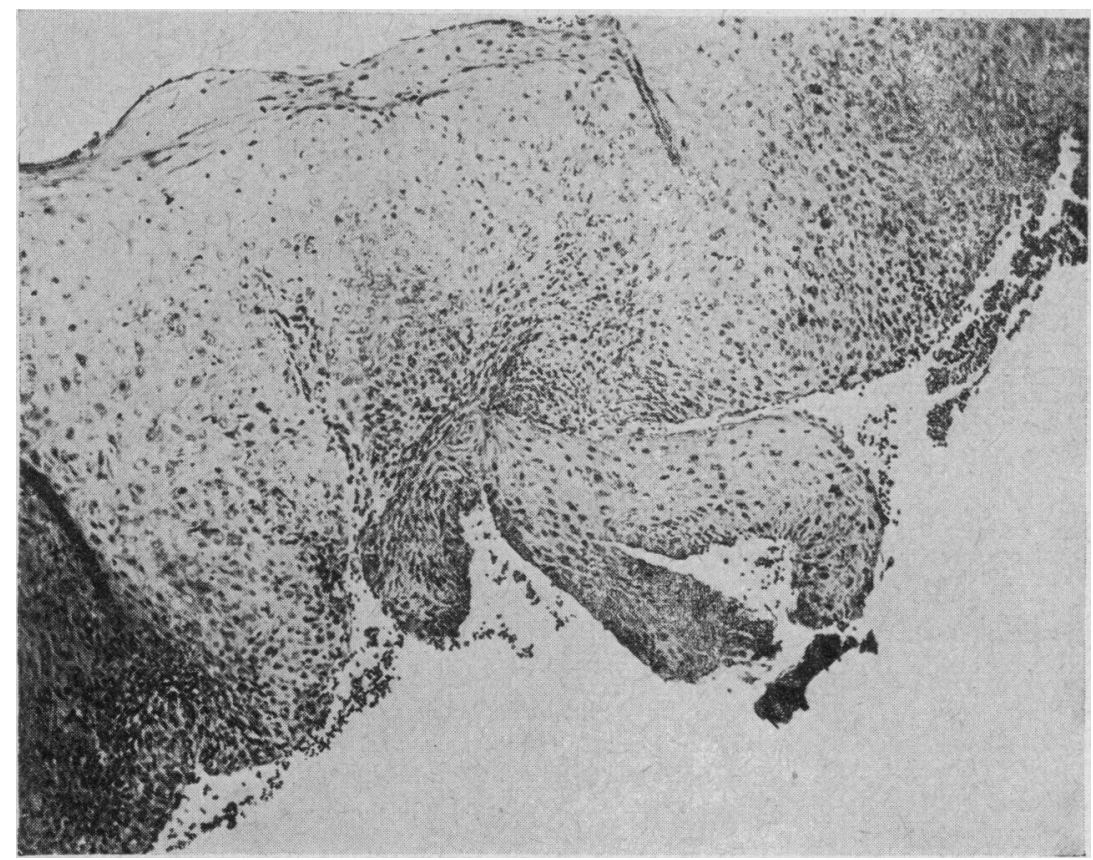

FIG. 3. $-\times 140$. 
Further Examination.--A tumour fragment was excised for microscopic examination; it was easily disjoined from the deep planes.

With low magnification (Fig. 3) a considerable thickening of the epithelium by proliferation of the epithelial cells was observed. The tumour, 1 to $1.5 \mathrm{~mm}$. in breadth, presented a flat surface; in one place, however, there was a clearlydefined extension formed by an epithelial proliferation into depth. In front of this formation conjunctival tissue was observed, in the midst of which could be seen a vessel penetrating between the epithelial cells close to the surface. This was one of the vessels in which the tumour follicles centred. The basal membrane everywhere was well preserved.

With high magnification (Fig. 4) one could see that the normal arrangement of the epithelial cells was disturbed. In some places, especially near the

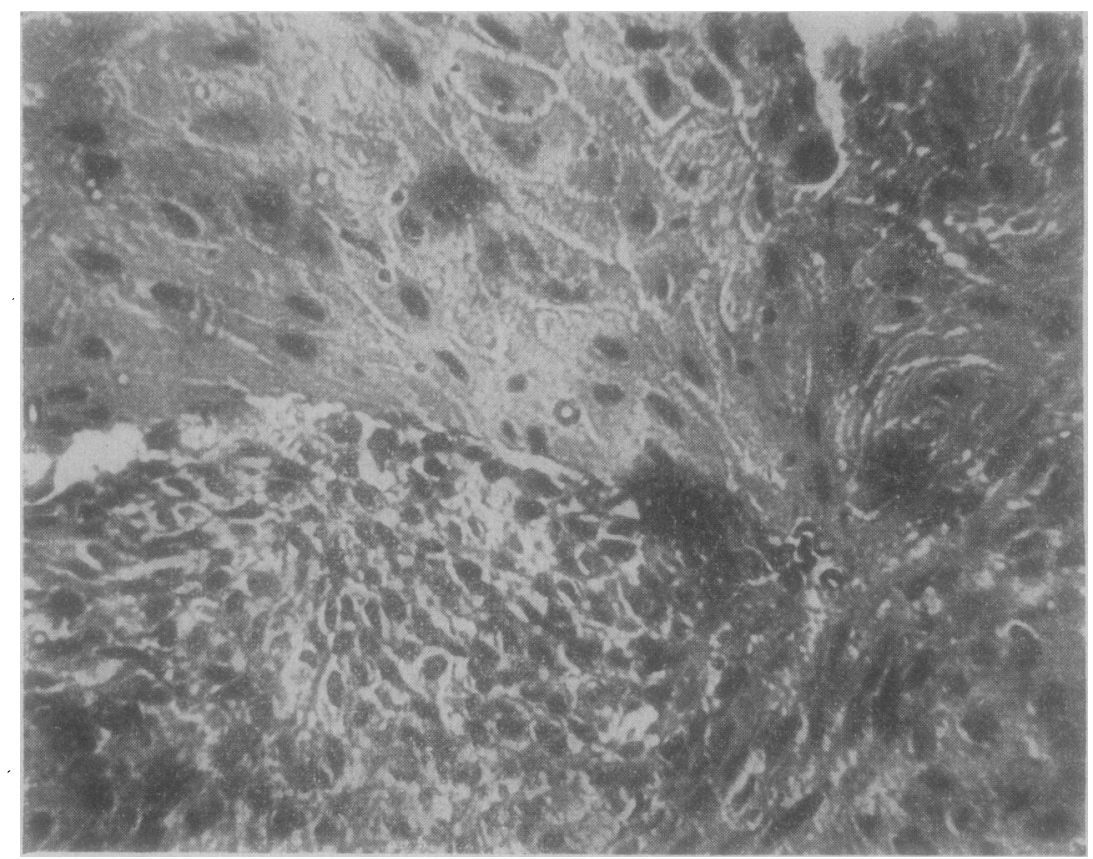

IIIG. $4 .-\times 800$.

extension into depth, the cells were small and showed very chromatic nuclei. In other places, the cells were greater and presented pale and more or less irregular nuclei, containing one or two clearly-defined nucleoli. The binuclear cells were numerous. Here and there mitosis was to be seen. There was no keratinization nor epithelial pearls. Some polynuclears were to be found in between the epithelial cells.

This is a typical picture of intra-epithelial epithelioma (Bowen's disease). We did not, however, see any giant cells; this was also the case with Esterman, Laval, and Okrainetz.

The rather peculiar presence of an extension into depth indicated an increase in the malignity of the tumour, as it could be observed also in the tumour of Bowen (Khanolkar, 1946). 
Therapy.-Our patient was submitted at once to contact radiotherapy in the service of Prof. De Backer: Philips Metalix tube; 50 kilovolts tension under 2 milliamp.; no filter; D.F.P. $40 \mathrm{~mm}$; surface of the localizator, lead; duration, 9 seconds; $51 \mathrm{r}$ per session; sessions on May 23, 24, 25, 27, 28, 30, 31, and June 1,3 and 7,10 sessions in all; total $5 \cdot 150 \mathrm{r}$.

Results.-On June 15 a very great improvement was noted (Fig. 5); the tumour had melted; the edge of the -cornea was back to its normal gleaming aspect. There was no opacification outside the circular banal gerontoxon. On the level of the conjunctiva it was impossible to see any neo-formation; there remained only a scarcely perceptible thickening with rather prongunced local hyperaemia.

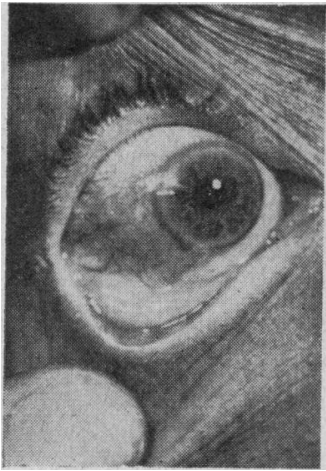

FIG 5,-June 15 .

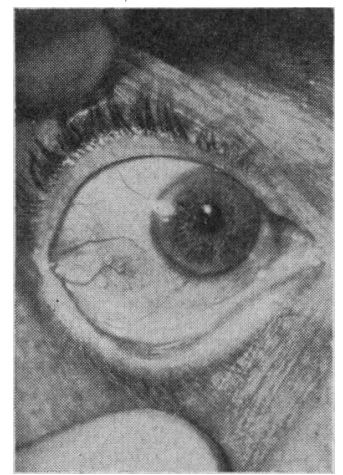

FIG. 6.-July 7 .

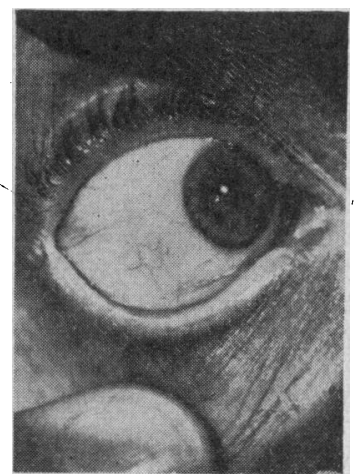

FIG. 7.-July 27.

On July 7 there was no trace of humour left and the hyperaemia had considerably diminished (Fig. 6).

On July 27 recovery was complete, with no sequela whatsoever (Fig. 7). The eye is white and it is impossible to tell that it has ever shown any lesion. It has responded splendidly to contact therapy, no trace of which is left, not even the slightest symptom of irritation. Visual acuity is still $10 / 10$. All refractive areas and the crystalline lens in particular remain absolutely transparent and there is no lesion of the inside of the eye.

$U_{p}$ to the present (i.e., after 6 months), recovery remains total without any sign of relapse.

Our observation of intra-epithelial epithelioma of Bowen is interesting for three reasons :

(1) Though one comes across Bowen's disease fairly often on the level of the skin, it is very seldom to be observed on the level of the bulbar conjunctiva. Ours is the ninth case published.

(2) Contact therapy brought about a rapid and complete recovery, which is the second one obtained by this method, the first being that related by Esterman, Laval, and Okrainetz. These authors used a Chaoul tube; 60 kilovolts tension under 5 milliamp.; no filter; D.F.P. $10 \mathrm{~cm}$.; $610 \mathrm{r}$ a minute; duration 1.5 minutes; one session every two days; nine sessions, total $5 \cdot 400 \mathrm{r}$. 
(3) The eye has undergone contact therapy without the slightest damage. This is not so when one resorts to the usual radiotherapy, which inflicts ocular irritation and often opacifies the crystalline lens.

Therefore we advise contact radiotherapy in every case of intraepithelial or even basocellular epithelioma of the bulbar conjunctiva.

\section{REFERENCES}

Collins, E. T. (1915). Trans. ophthal. Soc. U:K., 35, 215.

DUKE-Elder, S. (1946). "Text-book of Ophthalmology", Vol. 2, p. 1782. Kimpton, London.

Esterman, B., Laval, J., and Okrainetz, C. (1947). Amer. J. Ophthal.. 30, 1537.

Heckel, E. B. (1922). Arch. Ophthal., Chicago, 43, 237.

Khanolkar, V. R. (1946). Amer. J. Ophthal., 29, 515.

Mattice, A. F. (1914). Arch. Ophthal., Chicago, 43, 237.

MCGAvic, J. S. (1942). Amer. J. Ophthal., 25, 167.

MÉRIGÓt DE TREIGNY, P. In "Traité d'Ophtalmologie", ed. Bailliart and others, t. 4, p. 643. Masson, Paris.

RADOS, A., and Schinz, H. R. (1922). Graefes Arch. Ophthal., 110, 370.

Wise, G. (1943). Amer. J. Ophíhal., 26, 167. 